\title{
Effectiveness of folklore as a means of early speech therapy
}

\author{
Marina Skuratovskaya ${ }^{1, *}$ and Elena Klimkina ${ }^{1}$ \\ ${ }^{1}$ Don State Technical University, 344003, Gagarina str., 1, Rostov-on-don, Russia
}

\begin{abstract}
The article deals with the issue of mastering verbal and nonverbal means of communication by young children with delayed speech development. Modern ideas about the developing capabilities of folklore, its structural and speech features are analyzed. The results of diagnostics of the level of development of speech, expressive-mimic and subject-effective means of communication, sensorimotor and motivational-need levels of speech development of young children with speech development delay are presented.
\end{abstract}

\section{Introduction}

The period of early age is important in the development of a child's speech. It is at this age that the active accumulation of vocabulary occurs, and one of the important functions appears - the use of verbal means of communication, through which the child's knowledge and awareness of the world is carried out. This stage is one of the most important in human development. The child masters nonverbal and verbal means of communication, perceives speech patterns of close adults around him, which is necessary for building his own speech utterance [1-2].

The current situation shows an increase in the number of children with various speech disorders. The normal course of speech development is disrupted and requires the help of specialists (speech therapist, speech pathologist, psychologist, neurologist) [3-6].

The concept of the development of early care in the Russian Federation, adopted in 2016, reflects the relevance of the problem under consideration. At the state level, the tasks that were set, solved the creation of methodological recommendations and sample programs of psychological and pedagogical assistance to young children, the possibility of developing standards for early care and organization of the early care services in the subjects of the Russian Federation.

One of the important factors that ensure the success of a young child's speech acquisition is the presence of the emotional contact with the adults around him [7]. Through communication with close adults, the child becomes motivated to communicate with speech. The absence of emotional interaction, insufficient communication of the child with parents and close adults, are the reasons why the child is not able to master the necessary forms and means of communication. It is important to provide timely psychological and

* Corresponding author: marinasku@yandex.ru 
pedagogical assistance aimed at preventing and overcoming violations in the development of children's speech [6].

In the psychological and pedagogical literature, the issues of early speech development were studied in detail. The researchers have identified: the patterns of speech development at an early age [1,8-9]; the psycho-physiological and social conditions of successful language acquisition [5,7,10-11]; the factors leading to the disruption of speech development and manifestations of such disorders at an early age [4,6,12-13].

In order to prevent and develop speech communication in young children, we have identified small folklore genres. Having studied their structural and dynamic components and essential characteristics, we proved in our research, that it can be an effective tool, necessary in the correctional work of a speech pathologist [7,8]. For the development of the speech of a small child, the speech communication is important, which carries an emotional basis, and small folklore forms correspond to these characteristics.

We used small folklore works: round-dance games, songs, nursery rhymes, skips, jokes, nicknames, folk games. Thanks to their features, you can develop an emotional response, phonemic and musical hearing, develop motor coordination, enrich lexical units and to form communication in a dialogue with an adult, which helps to develop an understanding of the addressed speech, improve mental functions (attention, memory, thinking). After all, small folk forms can accompany the baby throughout the day: while feeding the baby, when putting it to bed, or encouraging the baby to stay awake.

Small folklore forms were systematized in accordance with the tasks of correctional work on the formation of verbal and non-verbal means of communication (table 1).

Table 1. groups of small folklore forms (SFF) in accordance with the tasks of correctional work on the formation of verbal and non-verbal means of communication.

\begin{tabular}{|c|c|}
\hline Tasks of correctional work & Groups of small folklore forms \\
\hline \multirow[t]{3}{*}{$\begin{array}{l}\text { Sensory-motor development of the child } \\
\text { and the stimulation of imitation }\end{array}$} & $\begin{array}{l}\text { - SFF providing the development of tactile } \\
\text { sensations, tactile interaction }\end{array}$ \\
\hline & - SFF ensuring the development of imitativeness \\
\hline & $\begin{array}{l}\text { - SFF provides the development of motor functions, } \\
\text { including the elements of massage }\end{array}$ \\
\hline \multirow{2}{*}{$\begin{array}{l}\text { Development of speech and speech } \\
\text { communication based on mastering non- } \\
\text { verbal and verbal means of } \\
\text { communication }\end{array}$} & $\begin{array}{l}\text { - SFF that require a non-verbal response and help } \\
\text { expand the range of non-verbal communication tools }\end{array}$ \\
\hline & $\begin{array}{l}\text { - SFF that require a verbal response, pronouncing a } \\
\text { syllable, word, or verbal dialogue }\end{array}$ \\
\hline
\end{tabular}

An adult performs a nursery rhyme and performs massage movements from the first days of his life (M. N. Melnikov). The child hears a poetic text performed by the parents. A jump always evokes a bright emotion in the baby, as the child sits on the lap of an adult and jumps, this is also accompanied by a poetic text of an adult, for example -"We were driving and came to the hole...".

A favorite folklore work can rightfully be considered a nursery rhyme. It is often used by teachers and accompanies the child throughout childhood. They actively involve the fingers of the hands, legs and other parts of the body, for example - "there Is a horned goat..." "Clap - Clap", "Magpie-crow porridge cooked". Researcher M. N. Melnikov in his writings characterized the nursery rhyme as a way to "amuse, amuse, amuse the child." Adults often sing it in a chant, for example: "Wow, flew on the head and sat down".

A more complex folk form is a joke, as it is a humorous story or expression. Children learn jokes when active speech is formed. The complexity of the structure pushes it to a later use, since it can be observed a bright event or an active action of the plot, and for its understanding, active concentration is necessary. A joke is good because it can contain one episode, which will allow the child to understand the content. 
Fables-shifters are included in folklore works for children. It is based on a logical error that amuses not only children, but also adults, which causes a positive emotional response laughter.

Many researchers claim that it is possible for children to get acquainted with this form of folklore when the child is familiar with the real world and events.

Another of the favorite small folklore forms of children is nicknames. They were performed by natural phenomena: the sun, wind, rain. Nicknames carry the historical experience when a person interacted with nature when performing a ritual. For example, referring to the rain asked for abundant watering of the crop. Singing these poetic texts, the child may feel connection with the surrounding world. The poem itself helps to develop a child's dialogue, enrich the vocabulary with lexical units. Researcher T. A. Peskisheva studying the MFF notes that it is the nicknames that help the child learn verbs in lines ("torment us, pies start"), nouns in the diminutive form of nouns ("Fly to the sky, bring me bread!").

The most common form of small folk forms is a rhyme and it accompanies the child not only in preschool age, but also throughout childhood. Most often, they are used by children to choose the driver in the game.

We singled out round dance games, as we believe they have a great potential for correctional speech therapy work with young children. Researcher M. N. Melnikov expresses concern about the death of this genre: "Radio, television, and movies from the side of meaningful and literary-musical and sports games have caused the inevitable death of children's games with game choruses."

In our opinion, small folklore forms can be an effective tool in correctional speech therapy work with young children. After all, thanks to their emotionality, rhythmicity, the presence of repetitions, small folk forms are interesting and understandable to the child. A joint performance of the text of folklore forms and corresponding movements with an adult makes it easier to remember them, encourages imitation of both the word and the movement $[7,8]$.

At the same time, we have not been able to find any special studies devoted to the study of the correctional capabilities of small folklore forms, their use as a means of developing verbal and non-verbal means of communication in young children.

Pedagogical research related to the use of folklore was mainly aimed at studying the possibility of their use in the development of children with normative development. Here we should mention the work of L.N. Pavlova, devoted to the study of the developing capabilities of folklore in working with young children. The author singled out such features of folklore as melody and melodiousness, emotionality and repeatability of the text. These features, according to L. N. Pavlova, determine the excellent possibilities of folklore as a means of speech development of the child. Modulations of the adult's voice, his movements and expressed emotionality affect the natural orientation reflex of the child and help to attract his attention to the adult for a long time, what he says and what movements he performs. And in combination with the rhythmic repetition of movements and speech material of small folk forms, the basis for the development of the child's general and speech imitativeness is created. The special rhythmic structure of speech material allows you to use it starting from the first months of a child's life. Already in the process of walking, small folk forms stimulate the child to pronounce vowels. Later, during the babbling period, the child tries to repeat the syllables. And from the second year of life words, and then - phrases.

It should be noted that most of the works that consider the developmental possibilities of folklore are aimed at preschool children. At the same time, different authors considered different aspects of the use of small folklore forms in the development of preschool children. Thus, in the study of M. N. Bratukhina, the main attention was paid to the 
development of artistic creativity in preschool children in the process of getting acquainted with folk art. The author noted the importance of matching the works of folklore to the age characteristics of children, the need for their use at all age stages of child development. The result of such work, in her opinion, should be knowledge of works of folklore, the ability to use speech material of small folk forms in their own speech and in retellings, dramatizations of works of folklore, in artistic activities.

T. V. Antonova's Research proved the importance of including folklore in the emotional moments of playing together with an adult. The importance of folklore as a means of developing verbal creativity and its expressiveness was noted in the works of O. V. Akulov, M. N. Bratukhin, and M. V. Fadeev.

A number of studies have investigated the use of the folklore in working with preschool children with disabilities. For example, L. V. Lopatina, N. V. Serebryakova, A. E. Ivanova, T. A. kotlyakova and I. A. Rybkina noted the possibility of using small folklore forms for the correction of speech disorders in preschool children. T. A. Peskisheva, has developed the methodological recommendations for the use of small folklore forms in correctional work with preschool children with speech development disorders.

The use of folklore was also considered in relation to the education of children with autism spectrum disorders. N. L. Belopolskaya and O. V. Ruban confirmed the possibility and effectiveness of using such folklore forms as nursery rhymes, round-dance games and lullabies in working with this category of children. The authors paid special attention to round-dance games. According to the authors, round-dance folklore helps to ensure interaction on the verbal and non-verbal levels. It includes unifying actions, rules, as well as rhythm and image. It is easy to provide emotional, visual, and physical contact during round dance games. All these features of choral folklore allowed the authors to evaluate it as a method of correcting communication disorders.

According to O. V. Ruban, the basis of the method of correctional work with children with disabilities using pestles is the traditional methods of interaction between mother and child. She has developed basic rules for the conduct of remedial classes with the use of verses of hopscotch, defined requirements for the organization of such activities. Among the main rules, O. V. Ruban referred to the need for a variety of folklore works used, control over the position of the child in the mother's arms during the lesson, repeatability and cyclical rhythms. The author considers systematic and systematic training, the work of two specialists simultaneously for individual support of the child, and a special organization of the developing environment to ensure the child's concentration on the game to be the conditions for the effectiveness of using the method of nurturing. In the study, O. V. Ruban also systematized folklore material in accordance with the tasks of correctional work: pestles that require only a non-verbal or verbal response, pestles aimed at developing the child's motor skills (with elements of massage, aimed at tactile interaction, the development of the vestibular apparatus, motor imitation).

Y.A. Razenkova noted such significant features in a correctional work with children of early age with limited opportunities of health, such as melodiousness and repeatability of rhythm, regularity and deliberation. These features make it possible to convey maternal love through the intonation expressiveness of small folk forms.

I would like to note the study of T. A. Pesshikova, which revealed the content of correctional work using small folklore forms with preschool children with severe speech disorders. The author formulated such conditions for conducting classes using folklore works as a differentiated approach to choosing works of folklore depending on the characteristics of the child's development, simultaneous work on the development of sensorimotor, speech and cognitive functions, the sequence and stage-by-stage development of folklore works. Pesshikova described methods and techniques for including small folk 
forms (nursery rhymes, sayings, folk games, songs) in such types of speech therapy work as articulatory gymnastics and automation of sounds.

The results of our analysis of psychological and pedagogical research in the field of the use of folklore in correctional work indicate that this problem was considered mainly in relation to preschool children. We have not been able to find special studies on the possibilities of using small folklore forms as a means of developing verbal and non-verbal means of communication in young children with delayed speech development. There have also been no studies that reveal the peculiarities of mastering verbal and non-verbal means of communication in young children with delayed speech development. This determined the purpose of our study - to study the features of children's development of the third year of life with delayed speech development by verbal and non-verbal means of communication. In the course of our research, we started from the understanding of speech as a complex system that includes structural and dynamic components. The study involved 64 children of the third year of life with speech retardation.

\section{Methods}

At the first stage of diagnosis, anamnestic data was analyzed in order to identify social and biological risk factors for speech development disorders, and to obtain information about the features of early speech and pre-speech development. At this stage we used the methods of analysis maps the development of the child and discussions with parents.

At the second stage of diagnosis, the study was conducted in three directions.

The first direction was associated with the study of the features of the motivational and need sphere of children. The evaluation criteria were the activity and initiative of the child in communicating with an adult.

The second direction involved the study of the sensorimotor level of speech. The criteria were the structure and mobility of the organs of articulation, auditory attention and phonemic hearing, the ability to distinguish sounds and onomatopoeia, as well as to recognize similar-sounding words. For the diagnostics we used the methodology of E. A. Strebeleva. The third direction was to study the peculiarities of possession of verbal and non-verbal means of communication. The evaluation criteria were the understanding and use of speech, expressive-mimic, and subject-effective means of communication. When studying expressive and mimic means of communication, we paid attention to such indicators as the presence of eye contact, smiles, laughter, negative emotions of discontent, resentment, expression of facial expressions, and the use of expressive gestures. In the study of subject-effective means of communication, the main diagnostic indicators were the presence of expressive actions aimed at organizing, maintaining joint activities, demonstrating their own activities, the desire to interest an adult in joint activities, requests related to any activity - to submit, help, play. Diagnostic methods were used by E. A. Strebeleva, O. E. Gromova, O. G. Solomatina, as well as a test of speech and communication development.

Quantitative and qualitative analysis of the results obtained allowed us to come to the following results.

\section{Discussion of results}

Based on the results of diagnostics at the first stage, it was revealed that most children had a history of prenatal and Natal pathology. At an early age, there is a delay in the development of motor, pre-speech, and speech functions (humming, babbling, and the beginning of phrasal speech formation). 
The results of diagnostics at the second stage showed the following. In the motivationalneed sphere, the majority of children showed low interest in communicating with adults. Only $20 \%$ of children were able to show initiative and activity in communication and play with adults. In most cases, children could not take the initiative in organizing a game with an adult. In the best case, they could engage in game interaction on the initiative of an adult.

The study of the sensorimotor level of speech development revealed a low level of development in most children. Difficulties were manifested in violation of the accuracy, volume of movements of the organs of articulation, the inability to repeat movements by imitation. Violations of phonemic functions associated with difficulties in distinguishing non-speech sounds, onomatopoeia, and words that are similar in sound were also identified.

The results of diagnostics of speech communication tools revealed a significantly higher level of development of understanding of speech tools than the level of their use. The greatest difficulties were associated with understanding of verbs and differentiating singular and plural nouns. Some children with a low level of understanding of speech means showed negative reactions when repeated instructions from the teacher.

The active speech of the studied group of children was characterized by frequent use of facial expressions and gestures, onomatopoeia words, babbling words and root words. The use of verbs, adjectives, and adverbs was particularly restricted. Most of the children did not have phrasal speech, or they used a babbling phrase or a phrase with gestures, onomatopoeia, and root words. There were frequent errors in the use of words, substitutions of words both in meaning and in sound. Low level of active speech development was predominant.

\section{Conclusions}

Our analysis of the diagnostic results revealed a significant lag in children with delayed speech development in all areas of diagnosis. Low indicators were found in the development of motivational sphere, sensorimotor functions, as well as in the development of speech, expressive-mimic and subject-effective means of communication. But the biggest lag behind the normative indicators was typical for the development of speech communication tools. First of all, this was manifested in the difficulties of mastering phrasal speech and grammatical categories. The close relationship and interdependence in the development of all levels of speech development is shown in the following. The low level of motivation and needs led to a significant violation in communication with adults and to a delay in the development of General and speech imitativeness. As a result, children were delayed in mastering verbal and non-verbal means of communication.

The results of our research allowed us to come to the conclusion about the need for targeted work in several areas. These include the formation of not only verbal and nonverbal means of communication, but also the development of the motivational and need sphere, sensorimotor level of speech, General and speech imitativeness, which are the basis for the development of speech communication of the child. In our opinion, small folklore forms can become an effective means of such work, due to their structural and content features.

\section{References}

1. P. Salvago, E. Gorgone, S. Giaimo, E. Battaglia, F. Dispenza, S. Ferrara, F. Martines, International Journal of Pediatric Otorhinolaryngology, 126, 109602 (2019) doi: https://www.sciencedirect.com/science/article/abs/pii/S0165587619303362 
2. T. Özdaş, A. Sanem Şahlı, B. S. Özdemir, E. Belgin, Brazilian Journal of Otorhinolaryngology, 85 , 199-205 (2019) doi:https://www.sciencedirect.com/science/article/pii/S1808869417302227?via\%3Dih $\mathrm{ub}$

3. V. Tumanova, E. G. Conture, E. W. Lambet, T. A. Walden, Journal of Communication Disorders, 49, 25-41 ( 2014) doi: https://doi.org/10.1016/j.jcomdis.2014.01.003

4. E. I. Toki, J. Pange, Procedia - Social and Behavioral Sciences, 2, 4274-4278 ( 2010) doi: https://www.sciencedirect.com/science/article/pii/S1877042810007184

5. O. L. Lekhanova, O. A. Glukhova, Nonverbal Encoding and Decoding of Nonverbal Communication Means as a Condition of Reflection Development in Communication in Children with Speech Underdevelopment, 233, 504-507 (2016) doi: https://www.sciencedirect.com/science/article/pii/S1877042816314380

6. S. Hearnshaw, E. Baker, N. Munro, Journal of Communication Disorders, 71, 61-71 (2018) doi: https://www.sciencedirect.com/science/article/abs/pii/S0021992417300679

7. M. L. Skuratovskaya, E. A. Klimkina, Content and organization of speech therapy diagnostics of young children with speech development delay. - Proceedings of the southern Federal University. Pedagogical Sciences, 10, 119-125 (2016)

8. M. L. Skuratovskaya, E. A. Klimkina, Overcoming the delay in speech development in young children during correctional work using small folklore forms. Bulletin of the Leningrad state University named after A. S. Pushkin, 4, 223-230 ( 2018)

9. R. G.Gordon, L. R. Watson, International Encyclopedia of the Social \& Behavioral Sciences (Second Edition), 399-404 (2015)

10. M. van Heugten, D. R. Krieger, E. K. Johnson, The developmental trajectory of toddlers' comprehension of unfamiliar regional accents, 11, 41-65 (2015) doi: https://www.tandfonline.com/doi/full/10.1080/15475441.2013.879636

11. G. W. McRoberts, Encyclopedia of Infant and Early Childhood Development, 267-277 (2020) https://www.sciencedirect.com/science/article/pii/B978012809324523616X?via\%3Dih $\mathrm{ub}$

12. D. E. Bernier, K. S. White, Journal of Experimental Child Psychology, 185, 128-147 (2019)

13. H. Chung, K. Farr, K. E. Pollock, Journal of Communication Disorders, 80, 18-34 (2019)

doi:https://www.sciencedirect.com/science/article/abs/pii/S0021992418301205?via\%3 Dihub 